\title{
Studies on the Reaction of Thorium with Graphite at High Temperatures*
}

\author{
By Sakae Takeuchi,** Toshio Honma** and Tsuneo Satow**
}

\begin{abstract}
The reaction of thorium metal with graphite was studied in the temperature range of $900^{\circ} \mathrm{C}$ to $1600^{\circ} \mathrm{C}$. It was found that the reaction rate was parabolic and the activation energy for the reaction was $53 \mathrm{kcal} / \mathrm{mole}$ below $1200^{\circ} \mathrm{C}$. Marker experiments showed that the growth of the carbide film was due mainly to the migration of carbon. From these results the rate determining process of the reaction seems to be the diffusion of carbon through the carbide film formed on the metal surface. Hydrocarbons, yielded by hydrolysis of the carbide film, were analysed by the gas-chromatographic method, from which the ratio of $\mathrm{ThC}^{\mathrm{ThC}} \mathrm{Th}_{2}$ in the carbide film was determined. The film formed below $1200^{\circ} \mathrm{C}$ was composed of $\mathrm{ThC}$ only. However, in the film formed above $1300^{\circ} \mathrm{C}$ the ratio of $\mathrm{ThC} / \mathrm{ThC}_{2}$ decreased with increasing temperature. These results were confirmed by the X-ray diffraction technique. Parabolic rate constants for $\mathrm{ThC}$ and $\mathrm{ThC}_{2}$ formations and apparent rate constants for the carbide film growth were obtained from the rate constant of the total carbide formation and the $\mathrm{ThC} / \mathrm{ThC}_{2}$ ratio in the carbide. The activation energy for the $\mathrm{ThC}_{2}$ formation was found to be $120 \mathrm{kcal} /$ mole from the results above $1300^{\circ} \mathrm{C}$. The diffusion coefficient of carbon in ThC was calculated from the rate constants for the carbide formation. The amount of thorium carbide which forms in a thorium blanket of a graphite matrix fuel reactor was estimated.
\end{abstract}

(Received February 4, 1964)

\section{Introduction}

Thorium will be used as a fertile material for power reactors in the near future and graphite is a good structural material as well as a useful moderator especially for high temperature reactors. However, it is not clear how metallic thorium and graphite react when they are brought into contact with each other at high temperatures.

In such a solid reaction, if the product of the reactions is accumulated as a compact surface layer on the solid element, the reactant material must be transported through the product layer to continue the reaction. In this case, the rate of the reaction is controlled by either the reaction velocity at the interface of the layer or the diffusion velocity of the reactant materials through the layer. In the former case the growth of the layer is independent of thickness and gives a linear growth law, but in the latter case, a parabolic law is to be expected in general. (In the case of oxidation, when the film thickness of the product is very thin it is recognized that cubic, reciprocal logarithmic and other laws are applicable, but if the film grows to a certain thickness near $1000 \mathrm{~A}$, the parabolic law is applicable in general.(1)) Besides, it is necessary to take into consideration what is the main diffusing element through the product layer and which growth rate determines the overall reaction rate when the product is composed of more than two successive layers.

In this investigation the reaction rate and the motion of markers were measured to find the reaction mechanism of thorium and graphite at high tempera-

* This paper Publised Originally in Japanese in the Journal of the Japan Institute of Metals, 27 (1963), 278

** The Research Institute for Iron, Steel and Other Metals,

Tohoku University, Sendai, Japan

(I) N. Cabrera, N.F. Mott: Rep. Prog. Phys., 12 (1949), 163.

Trans. JIM tures. Moreover, the diffusion coefficient of carbon in thorium mono-carbide was calculated from the parabolic rate constant.

\section{Experiments and Results}

\section{Measurement of the reaction rate}

(1) Experimental procedure

When thorium is kept in contact with graphite at high temperatures, the carbide film apperars on the surface of the metal. Moreover, the molecular volumes of both carbides, $\mathrm{ThC}$ and $\mathrm{ThC}_{2}$, are larger than the atomic volume of the metal. Therefore the film formed on the surface will be coherent and compact. The rate of the carbide film formation is considered to follow either a parabolic or a linear law. A piece of thorium metal was kept in contact with graphite for $3 \mathrm{~min}$ to $50 \mathrm{hr}$ in vacuum in the temperature range of $900^{\circ}$ to $1600^{\circ} \mathrm{C}$ to determine the amount of the carbide formed.

Thorium metal was buried in graphite powder, and the cylinder $(8 \mathrm{~mm} \phi$, ca. $10 \mathrm{~mm}$ high $)$ was made at a compacting pressure of 2.5 tons $/ \mathrm{cm}^{2}$. The dimensional changes of the thorium produced by the pressing were smaller than the error in measurement of the length by a micrometer. The samples were kept in vacuum (ca. $10^{-4} \mathrm{mmHg}$ ) for about $30 \mathrm{~min}$ at room temperature, heated gradually up to $200^{\circ} \mathrm{C}$ to eliminate the adsorbed gases and moisture, and then heated rapidly to the fixed temperature in a $\mathrm{SiC}$ resistance furnace. Samples to be heated higher than $1300^{\circ} \mathrm{C}$ were heated in a high frequency induction furnace to obtain the results of a short time heating. In the former case the temperature was controlled by a thermoelectric temperature controller and was measured by the Pt-PtRh thermocouple. In the latter case the temperature was controlled by changing the grid voltage of a thyratron tube and was measured by

1964 Vol. 5 
an optical pyrometer. In the case of $1300^{\circ} \mathrm{C}$ the high frequency furnace was used for 1 and $2 \mathrm{hr}$ heating, and the $\mathrm{SiC}$ furnace for 5 and $16 \mathrm{hr}$ heating. It is thought that the difference between the two methods can be disregarded as their results showed no contradictions of each other.

After cooling in the furnace, the sample was kept about one hour in warm water $\left(\mathrm{ca} .50^{\circ} \mathrm{C}\right)$ to decompose the carbide. It is known that $\mathrm{ThC}_{2}$ is hydrolysed into thorium oxydaquat $\left(\mathrm{ThO}_{2} \cdot \mathrm{xH}_{2} \mathrm{O}\right)$ and hydrocarbons ${ }^{(2)}$, and that the hydrolysed product of ThC changes into $\mathrm{ThO}_{2}$ by heating in air. Therefore, the amount of thorium reacted was determined from the weight of $\mathrm{ThO}_{2}$ yielded by calcination of the hydrolysed product. This amount agreed well with the amount obtained from the weight loss of the metal. The solubility of carbon in thorium increases with temperature, (3) but the errors from this source may be neglected as the carbide dispersed in the metal cannot be easily hydrolysed.(4)

\section{(2) Samples and materials}

The thorium metal was prepared in this laboratory by fused salt electrorefining of the metal which had been reduced from $\mathrm{ThO}_{2}$ with calcium. ${ }^{(5)}$ The metal powder was arc melted in argon atmosphere, cold rolled, annealed, and machined. The surface of the pieces $(3 \times 5 \times 1.5 \mathrm{~mm})$ was smoothed by 05 emery paper. The surface area was calculated from the lengths of the three edges measured by a micrometer. Impurities present in the metal are given in Table 1. The graphite

Table 1 Impuirities contained in the thorium metal.

\begin{tabular}{c|c|c|c|c|c|c|c}
\hline \hline Elements & $\mathrm{C}$ & $\mathrm{Fe}$ & $\mathrm{Mo}$ & $\mathrm{Si}$ & $\mathrm{Ca}$ & $\mathrm{Al}$ & $\mathrm{Cu}$ \\
\hline $\mathrm{wt} \%$ & 0.01 & 0.01 & 0.01 & 0.005 & 0.003 & 0.002 & 0.001 \\
\hline
\end{tabular}

used in this investigation was 100 to 200 mesh powder which was the by-product of the silicon carbide production. When silicon carbide was produced by a direct heating method, the temperature of the center of the silicon carbide becomes so high that the silicon disappeared and the carbon graphitized. This was purified to a reactor grade, cracked, and sieved. Crystal growth of the graphite is as good as natural graphite so that the graphite cylinder having enough strength to handle can be made by pressing without any binder. The powder was dried for about $24 \mathrm{hr}$ at $120^{\circ} \mathrm{C}$ before use.

\section{(3) Experimental results}

Experimental results are plotted in Fig. 1 which show the linear relations between the amount of thorium metal reacted with graphite per unit area and the square root of the reaction time. This means that the

(2) Gmelins Handbuch der Anorganischen Chemie Thorium, (1955), s. 300

(3) R. Mickelson, D. Peterson: Trans. ASM, 50 (1958) 340

(4) H.A. Wilhelm, P. Chiotti: Trans. ASM, 42 (1950), 1295

(5) S. Takeuchi, S. Kachi, T. Satow: J. Japan Inst. Met. (in Japanese), 23 (1959), 336, 393

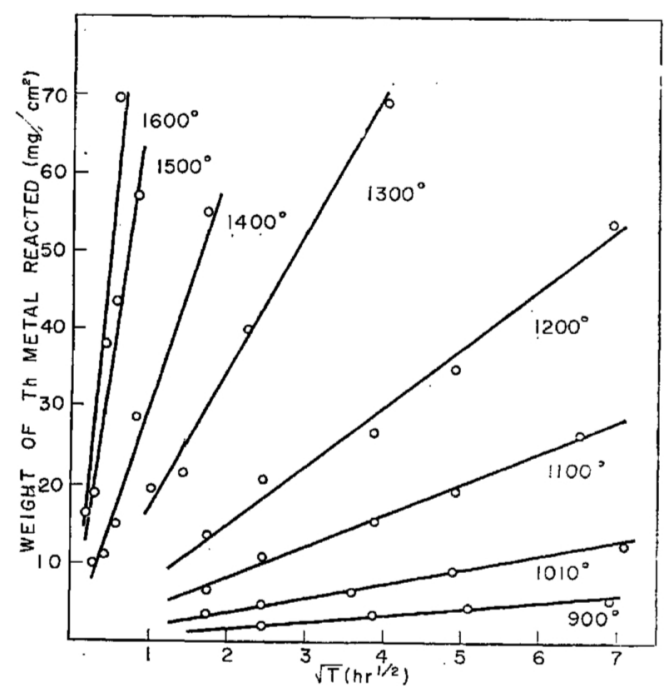

Fig. 1 Reaction time vs. weight of thorium combined with carbon per unit area.

reaction proceeds according to the parabolic law. Parabolic rate constants were obtained from them and are plotted in Fig. 2. Data in the low temperature range lie on a straight line a. The activation energy for the reaction was $53 \mathrm{kcal} /$ mole below $1200^{\circ} \mathrm{C}$.

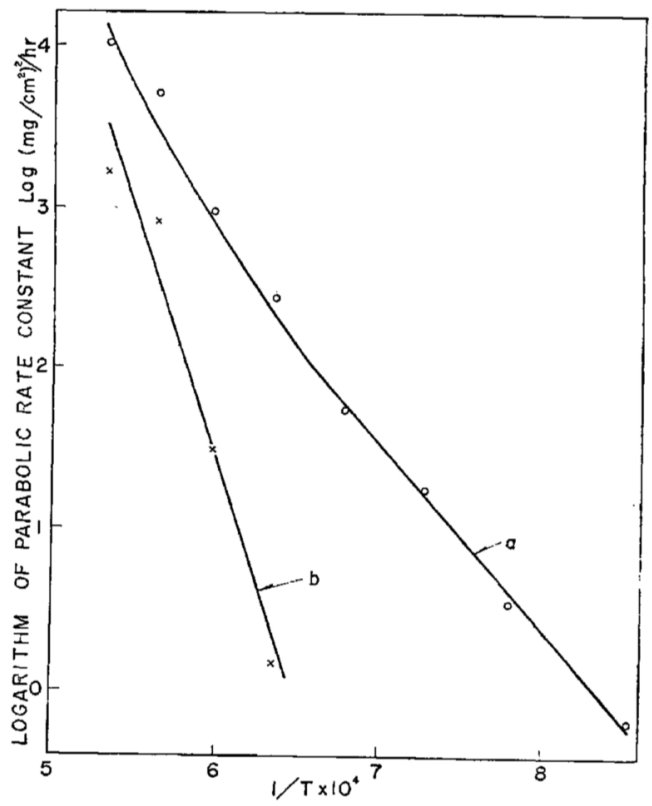

Fig. 2 Temperature dependence of the parabolic rate constant for the carbide film growth.

a: rate constants for total carbide film. growth

b: rate constants of $\mathrm{ThC}_{2}$ film growth calculated from equation (12)

\section{Confirmation of diffusing elements by marker tests}

The fact that the reaction follows the parabolic law shows that the rate-determining step is the diffusion of the reactant ions or atoms through the carbide film formed on the metal surface. It can be inferred from the atomic radii that the diffusion velocity of carbon is larger than that of thorium, but this remains unconfirmed. A piece of thorium was held between two graphite plates, fine tungsten wires 
were placed between the thorium and graphite, and the system was held at $1200^{\circ} \mathrm{C}$ for $48 \mathrm{hr}$. From the increase in distance between the two tungsten wires, it was concluded that the mass was transferred mainly from graphite to thorium. Furthermore, the tungsten wire was at the contact surface of the carbide film and the graphite as shown in Photo. 1.

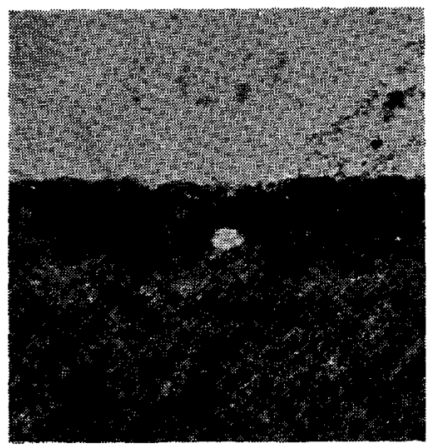

Photo. 1 Marker test for thorium-graphite reaction. $(\times 108)$

upper part: metallic thorium; middle part: carbide; lower part: graphite; white ellipse: section of tungsten wire $(20 \mu \phi)$

This fact shows that the main element moving through the carbide film is carbon.

\section{Confirmation of chemical species of the carbide film by gas-chromatography and X-ray diffraction}

The film formed should consist of $\mathrm{ThC}$ and $\mathrm{ThC}_{2}$ layers which are thought to be the only carbides of thorium. If the ratio of their film thicknesses is known, one can determine the formation rate constants of each film as will be described later. Furthermore these rate constants are determined by the diffusion constants of carbon through $\mathrm{ThC}$ or $\mathrm{ThC}_{2}$.

However, both carbides are so hygroscopic that it is very difficult to measure their thickness directly with an optical microscope or an electron probe micro analyser.

On the other hand, the composition of the hydrocarbon gas evolved by the hydrolysis of $\mathrm{ThC}$ and $\mathrm{ThC}_{2}$ at room temperature is known as shown in Table 2.(6) Although there are many reports ${ }^{(7)}$ on the gas composition, the data of Kempter et al. are used because of its good agreement with the authors' results with regard to hydrocarbons containing less than 3 carbon atoms $\left(\mathrm{C}_{3} \mathrm{H}_{x}\right)$. Quantitative analyses were performed under $\mathrm{C}_{3} \mathrm{H}_{x}$ only because activated alumina was used as the adsorbent. If hydrogen gas in their composition is not taken into account, the gas evolved from $\mathrm{ThC}$ consists largely of methane and the gas from $\mathrm{ThC}_{2}$ consists mainly of ethane. Thus, it is easy to determine the $\mathrm{ThC} / \mathrm{ThC}_{2}$ ratio in the carbide film using their composition. In this case, it is assumed that all the carbon contained in the carbides reacts to form gaseous hydrocarbons. This assumption is thought to be reasonable because the difference between total carbon and free carbon in the carbides agreed well with the content of carbon in the carbon dioxide obtained from the hydrocarbon evolved by hydrolysis of the carbide.

Assuming that no hydrocarbon molecules containing more than four carbon atoms are produced by hydrolysis, the numbers of moles of methane evolved from one mole of $\mathrm{ThC}$ and $\mathrm{ThC}_{2}$ are $0.898,0.024$, respectively; ethane is 0.024 from $\mathrm{ThC}$ and 0.302 from $\mathrm{ThC}_{2}$. Therefore, if the $\mathrm{CH}_{4 i} / \mathrm{C}_{2} \mathrm{H}_{6}$ ratio ( $=G$, mole ratio) in the hydrocarbon gas from the carbide is known, the $\mathrm{ThC} /$ $\mathrm{ThC}_{2}$ ratio ( $=m$, mole ratio) in the carbide film can be determined. Using the values mentioned above, the following relation is obtained:

$$
m=\frac{0.302 G-0.024}{0.898-0.024 G}
$$

The hydrocarbon gas evolved by the reaction of water and the resultant carbide film was collected. The $\mathrm{CH}_{4} / \mathrm{C}_{2} \mathrm{H}_{6}$ ratio was obtained by the gas-chromatographic method, from which the $\mathrm{ThC} / \mathrm{ThC}_{2}$ ratio was determined using the above equation. The results are shown in Table 3. Table 4 shows the $\mathrm{CH}_{4} / \mathrm{C}_{2} \mathrm{H}_{6}$ ratios in hydrolysed gases of $\mathrm{ThC}$ and $\mathrm{ThC}_{2}$ in comparison with the results reported by Kempter et al.

Activated alumina was used as the absorbent of gaschromatography because of its sharp separability for $\mathrm{CH}_{4}$ and $\mathrm{C}_{2} \mathrm{H}_{6}$. Conditions for gas-chromatography is as follows: column length, $3 \mathrm{~m}$; column temperature, $60^{\circ} \mathrm{C}$; carrier gas, hydrogen; flow rate, $60 \mathrm{cc} / \mathrm{min}$. The $\mathrm{C}_{4} \mathrm{H} / \mathrm{C}_{2} \mathrm{H}_{6}$ ratio was determined from the ratio of each peak height, which was compared with the results for a standard mixture of methane and ethane. ${ }^{(8)}$

In order to confirm these results, X-ray diffraction patterns of the surface film grown at various temperatures were obtained using glass capillaries and a

Table 2 Mass spetrographic results of $\mathrm{ThC}$ and $\mathrm{ThC}_{2}$ hydrolyses (mole \%) after Kempter et al.

\begin{tabular}{|c|c|c|c|c|c|c|c|c|c|c|c|}
\hline & $\mathrm{H}_{2}$ & $\mathrm{CH}_{4}$ & $\mathrm{C}_{2} \mathrm{H}_{2}$ & $\mathrm{C}_{2} \mathrm{H}_{4}$ & $\mathrm{C}_{2} \mathrm{H}_{6}$ & $\mathrm{C}_{3} \mathrm{H}_{4}$ & $\mathrm{C}_{3} \mathrm{H}_{8}$ & $\mathrm{C}_{4} \mathrm{H}_{6}$ & $\mathrm{C}_{4} \mathrm{H}_{8}$ & $\mathrm{C}_{4} \mathrm{H}_{10}$ & $\underset{\mathrm{C}_{4}}{\text { above }} \mathrm{H}_{X}$ \\
\hline ThC & 9.3 & 86.4 & & 0.75 & $2.3_{5}$ & \multicolumn{2}{|c|}{1.2} & & & & \\
\hline $\mathrm{ThC}_{2}$ & 27.2 & 2. $3_{5}$ & 9.5 & $2.4_{5}$ & 29.8 & 1.5 & 1.5 & 8.6 & 11.3 & 3.8 & 2.0 \\
\hline
\end{tabular}

(6) C.P. Kempter, N.H. Krikorian: J. Less-Common Met., 4 (1962), 244

(7) H. Moissan, A. Etard: Compt. rend., 122 (1896), 576; P. Lebeau, A. Damiens: Compt. rend., 156 (1913) 1987; I. Kanno, S. Kachi Nippon Kagaku Zasshi (in Japanese), 83 (1962), 565
Debye-Scherrer camera. As shown in Photo. 2, the sample at $1150^{\circ} \mathrm{C}$ gives strong lines of $\mathrm{ThC}$ and lines of graphite (200) and $\mathrm{ThO}_{2}(311),(422)$. It is con-

(8) "A.E. Messner, D.M. Roise, and P.A. Argabright: Anal. Chem., 31 (1959), 230. 


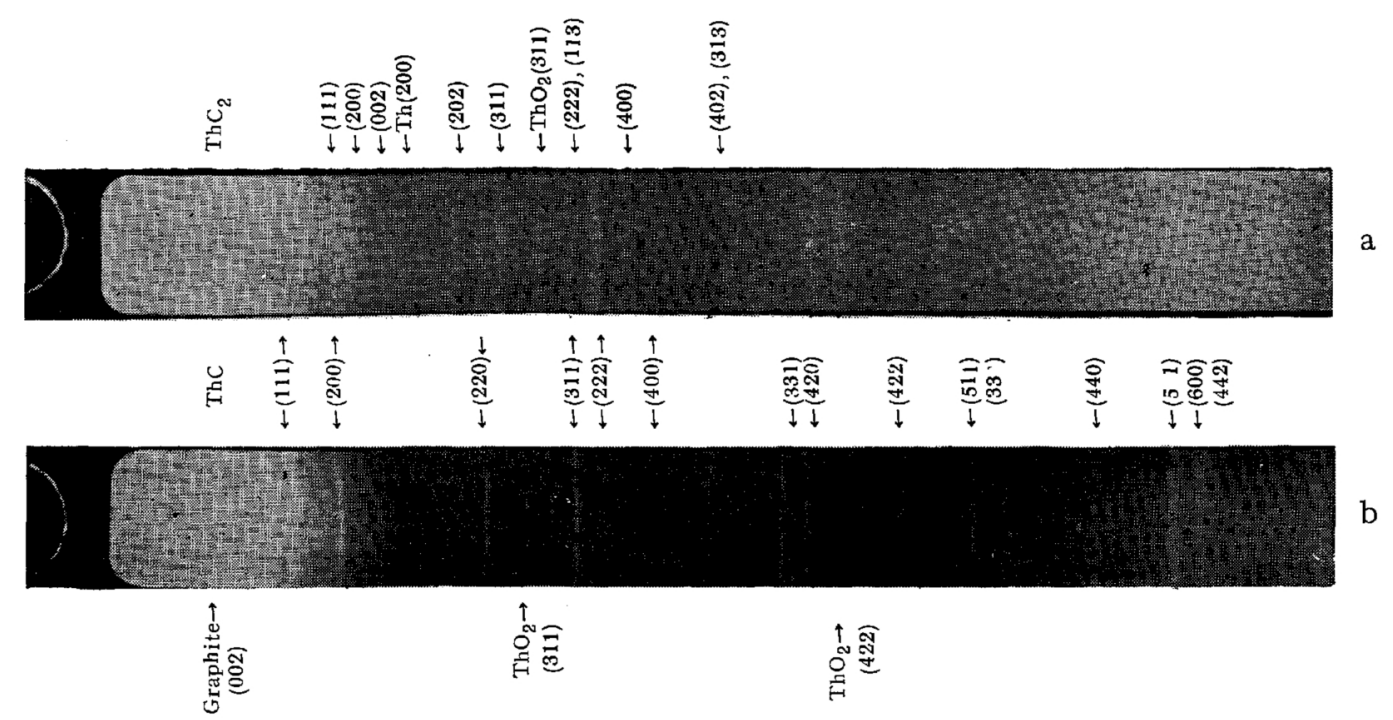

Photo. 2 X-ray patterns of the carbide film formed between thorium and graphite.

$$
\text { a: } 1400^{\circ} 2 \mathrm{hr} \quad \text { b: } 1150^{\circ} 40 \mathrm{hr}
$$

Table $3 \quad \mathrm{CH}_{4} / \mathrm{C}_{2} \mathrm{H}_{6}$ molar ratio in hydrolysed gases vs. $\mathrm{ThC}, \mathrm{ThC}_{2}$ molar ratio in the carbides.

\begin{tabular}{c|c|c}
\hline Temp. $\left({ }^{\circ} \mathrm{C}\right)$ & $\mathrm{CH}_{4} / \mathrm{C}_{\mathbf{2}} \mathrm{H}_{\mathbf{6}}$ & $\mathrm{ThC} / \mathrm{ThC}_{\mathbf{2}}(=\mathrm{m})$ \\
\hline 1600 & 3.9 & 1.4 \\
1500 & 4.1 & 1.5 \\
1400 & 9.8 & 4.5 \\
1300 & 18.9 & 12.8 \\
1200 & 35.6 & 244 \\
1100 & 37.0 & - \\
1010 & 39.3 & - \\
900 & 37.1 & - \\
\hline
\end{tabular}

Table $4 \quad \mathrm{CH}_{4} / \mathrm{C}_{2} \mathrm{H}_{6}$ molar ratios in hydrolysed gases of $\mathrm{ThC}$ and $\mathrm{ThC}_{2}$.

\begin{tabular}{l|c|c}
\hline \hline & $\mathrm{ThC}$ & $\mathrm{ThC}_{2}$ \\
\hline Calc. from Kempter results & 37.4 & 0.078 \\
Mean of present results & 37.8 & 0.074 \\
\hline
\end{tabular}

sidered that $\mathrm{ThO}_{2}$ was formed by the reaction of the carbide and atmospheric moistrure. Any lines of $\mathrm{ThC}_{2}$, even the lines (311), (220) (as tetragonal) which should not be screened by the lines of ThC and $\mathrm{ThO}_{2}$, were not found. The sample at $1400^{\circ} \mathrm{C}$ showed the presence of both $\mathrm{ThC}$ and $\mathrm{ThC}_{2}$.

\section{Discussion}

\section{Chemical species of the carbide film and their formation rate constants}

Jost ${ }^{(9)}$ and Haffe(10) discussed on the relation between the ratio of film thickness and the ratio of the formation rate constants under the simultaneous growth of two oxides on a metallic surface. Using the same assumptions and treatment, the formation rate

(9) W. Jost: Diffusion und Chemische Reaktion an Festen Stoffen, (1937), p. 162, 167, Theodor Steinkopff.

(10) K. Hauffe: The Surface Chemistry of Metals \&. Semiconductors (Edited by Gatos), (1960), 460 John Wiley $\&$ Sons. constants $k_{1}, k_{2}\left(\mathrm{~cm}^{2} / \mathrm{sec}\right)$ and the apparent parabolic rate constants $k_{p}^{\prime}, k_{p}^{\prime \prime}$ (number of $\left.\mathrm{Th} / \mathrm{cm}^{2}\right)^{2} / \mathrm{sec}$ of the two carbides can be derived from the $\mathrm{ThC} / \mathrm{ThC}_{2}$ molar ratio $(=m)$ and the parabolic rate constant of the total carbide formation. Let us assume (1) an equlibrium is reached at the boundaries, (2) the solid phases have no mutual solubility, (3) and the mass is transferred only by the diffusion process. As carbon diffuses through the carbide film towards the thorium metal, $\mathrm{ThC}_{2}$ forms at the $\mathrm{ThC}-\mathrm{ThC}_{2}$ boundary and ThC at the Th-ThC boundary. Therefore, the growth rate of the $\mathrm{ThC}$ film is determined from the difference between $\mathrm{ThC}$ formation and $\mathrm{ThC}_{2}$ formation, and the carbon available for the $\mathrm{ThC}_{2}$ formation is determined from the difference of transport currents in $\mathrm{ThC}_{2}$ and $\mathrm{ThC}$. Hence, the following equations are obtained :

$$
\begin{aligned}
& \frac{d n_{1}}{d t}=S_{1}-\left(S_{2}-S_{1}\right)\left(=\frac{k_{p}{ }^{\prime}}{n_{1}}\right) \\
& \frac{d n_{2}}{d t}=S_{2}-S_{1}\left(=\frac{k_{p}^{\prime \prime}}{n_{2}}\right),
\end{aligned}
$$

where $n\left(\mathrm{~cm}^{-2}\right)$ is the number of thorium per unit surface area of the carbide film in question, $S\left(\mathrm{~cm}^{-2} \mathrm{sec}^{-1}\right)$ is the transport current flowing through the carbide, ' or 1 and " or 2 designate $\mathrm{ThC}$ and $\mathrm{ThC}_{2}$ respectively. Since the sum of the amount of $\mathrm{ThC}$ and $\mathrm{ThC}_{2}$ is the total carbide amount,

$$
n_{1}+n_{2}=n \text {. }
$$

From equations (1), (2) and (3)

$$
\begin{aligned}
& \frac{d n}{d t}=S_{1} \quad\left(=\frac{k_{p}}{n}\right) \\
& S_{2}=\frac{d n}{d t}+\frac{d n_{2}}{d t}
\end{aligned}
$$

The ratio of film thicknesses is independent of time. Therefore, from equations (4) and (5)

$$
\frac{S_{2}}{S_{1}}=\frac{n_{2}}{n}+1
$$


If the formation rate is represented in terms of film thickness,

$$
\frac{S_{1}}{\alpha_{1}}=\frac{k_{1}}{\frac{n_{1}}{\alpha_{1}}}, \quad \frac{S_{2}}{\alpha_{2}}=\frac{k_{2}}{\frac{n_{2}}{\alpha_{2}}}
$$

where $\alpha\left(\mathrm{cm}^{-3}\right)$ is the number of thorium atoms contained in a unit volume of carbide.

As mentioned above, $n_{1} / n_{2}=m$.

From equations (4), (7) and (8), the following equations are obtained:

$$
\begin{aligned}
& k_{1}=\frac{m}{m+1} \cdot \frac{1}{\alpha_{1}^{2}} \cdot k_{p} \\
& k_{2}=\frac{m+2}{(m+1)^{2}} \cdot \frac{1}{\alpha_{2}{ }^{2}} \cdot k_{p} \\
& k_{p}{ }^{\prime}=\frac{m^{2}}{(m+1)^{2}} \cdot k_{p} \\
& k_{p}{ }^{\prime \prime}=\frac{1}{(m+1)^{2}} \cdot k_{p}
\end{aligned}
$$

Here, if the $\mathrm{ThC} / \mathrm{ThC}_{2}$ ratio in the carbide film and the rate constant for the growth of the total carbide film are known, the rate constants for each film formation and the apparent parabolic rate constants of each film growth can be obtained.

As shown in Table 3, almost all of the carbide film grown in the temperature range of $900^{\circ}$ to $1200^{\circ} \mathrm{C}$ is ThC. From the relation between the formation rate constant and the diffusion coefficient which will be shown later, it is clear that the diffusion rate of carbon through ThC is considerably larger than that through $\mathrm{ThC}_{2}$ in this temperature range. As given in Fig. 2, the plotted points of $\log k_{P}$ vs. $1 / T$ do not lie on a straight line above $1300^{\circ} \mathrm{C}$. It is thought that this is due to the following effect; the diffusion velocity of carbon through $\mathrm{ThC}_{2}$ becomes larger to an appreciable degree above $1300^{\circ} \mathrm{C}$, although it is much smaller than that through $\mathrm{ThC}$ below $1200^{\circ} \mathrm{C}$. Here, the apparent rate constants for the dicarbide film growth were obtained by equation (12) and were plotted in Fig. 2 with $\times$. The amounts of $\mathrm{ThC}$ and $\mathrm{ThC}_{2}$ in the carbide film grown at various temperatures can be obtained from these lines. Further, the rate constants for the $\mathrm{ThC}$ and $\mathrm{ThC}_{2}$ formation were obtained using equations (9) and (10), and were plotted in. Fig. $3\left(\alpha_{1}\right.$ and $\alpha_{2}$ were obtained using theoretical densities and molecular weights of the carbides). The slope for $\mathrm{ThC}_{2}$ gives an activation energy for the di-carbide formation as $120 \mathrm{kcal} / \mathrm{mole}$.

\section{Diffusion coefficient of carbon in thorium mono-carbide}

As mentioned above, the process of the carbide formation consists of the diffusion of carbon through the carbide film to the metal surface where it reacts. And the reaction rate is controlled by the diffusion velocity of carbon through the carbide. Therefore the diffusion coefficient of carbon can be derived from the rate constant.

Now, consideration will be given to the relation

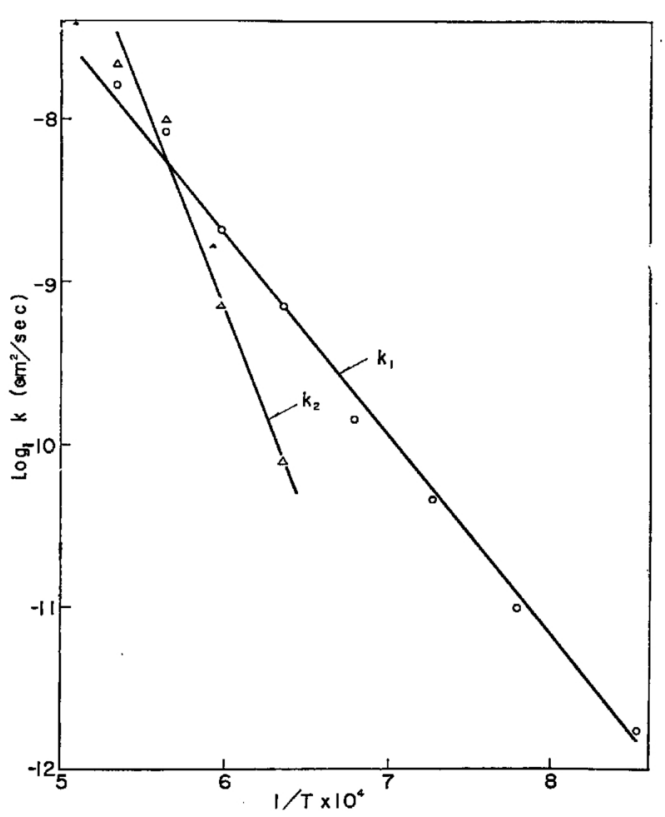

Fig. 3 Temperature dependence of the rate constant for monocarbide and di-carbideformations

between the rate constant and the diffusion coefficient as in the case of oxidation of metals. (11) The increase rate of the carbide thickness can be described as follows: $d x / d t=k_{1} / x$,

where $x(\mathrm{~cm})$ is the thickness of carbide film and $t$ (sec) is the reaction time. Considering a section of unit area, $\alpha_{1} d x / d t$ is the increase in the number of ThC molecules contained in the film during the time $d t$. This is equal to the number of carbon atoms reaching the metal surface and there reacting

$$
\therefore \quad \alpha_{1} \frac{d x}{d t}=D \frac{\partial c}{\partial x}
$$

where $D$ is the diffusion coefficient of carbon in thorium mono-carbide, and $C\left(\mathrm{~cm}^{-3}\right)$ is the concentration of

Table 5 Diffusion coefficients of carbon in ThC calculated from rate constants.

\begin{tabular}{c|l}
\hline \hline Temp. $\left({ }^{\circ} \mathrm{C}\right)$ & $D\left(\mathrm{~cm}^{2} / \mathrm{sec}\right)$ \\
\hline 1600 & $2.3 \times 10^{-8}$ \\
1500 & $1.3 \times 10^{-8}$ \\
1400 & $3.6 \times 10^{-9}$ \\
1300 & $1.3 \times 10^{-9}$ \\
1200 & $3.1 \times 10^{-10}$ \\
1100 & $9.5 \times 10^{-11}$ \\
1010 & $2.0 \times 10^{-11}$ \\
900 & $3.5 \times 10^{-12}$ \\
\hline
\end{tabular}

carbon. Here, provided that the stationary state is reached and the concentration gradient of carbon in the carbide film is constant,

$$
\frac{\partial c}{\partial x}=\frac{\left(c_{1}-c_{2}\right)}{x} \text {. }
$$

then, $k_{1}=D\left(C_{1}-C_{2}\right) / \alpha_{1}$

where $C_{1}$ and $C_{2}$ are the concentrations of carbon at the opposite sides of the film. The value $\left(C_{1}-C_{2}\right) / \alpha_{1}$

(11) C. Wagner: Z. phys. Chem., B 21 (1933), 25. 
was determined using the phase diagram ${ }^{(12)(4)}$ and then the diffusion coefficient of carbon through ThC is derived from the parabolic rate constant $k$, using the equation (9). This is shown in Table 5. In this case, the carbon which dissolves in the metal must be considered. Strictly speaking, it must be treated analytically. Referring to the Peterson's results ${ }^{(13)}$ on the carbon diffusion in thorium metal, the error estimated was found to be less than several percent and needed no correction.

3. The upper limit of temperature for using metallic thorium as a blanket material in a graphite matrix fuel reactor

The graphite matrix fuel reactor is one of the most promising power reactors. HGCR-1 in the United States, HTGCR in Great Britain, the pebble-bed type reactors in Germany and the United States, and SHGR, SHBCR in Japan are all graphite matrix fuel reactors. In these reactors the fuel material and the fertile material are dispersed in graphite powder. These reactors overcome the weak points in neutron economy of the homogeneous reactors and in heat transfer and fuel reprocessing of the heterogeneous reactors. Furthermore, they withstand higher temperatures than the current moderator or structural materials. For SHGR and SHBCR(14), thorium metal, thorium carbides or thorium oxide is used as the blanket material. Blanket materials are mixed in the form of powder with graphite powder or are held in the shape of a rod or plate between graphite blocks. In this case the thickness of the carbide film formed on the surface of metallic thorium in contact with graphite was obtained as a function of temperatire and time. It is possible that outside the range of experimental

(12) M. Hansen: Constitution of Binary Alloys, (1958), 381.

(13) D.T. Peterson:, Trans. ASM, 53 (1961), 765.

(14) JAERI: Semi-Homogeneous Bismuth Cooled Reactor SHBCR (2nd Report), (1960), 39.

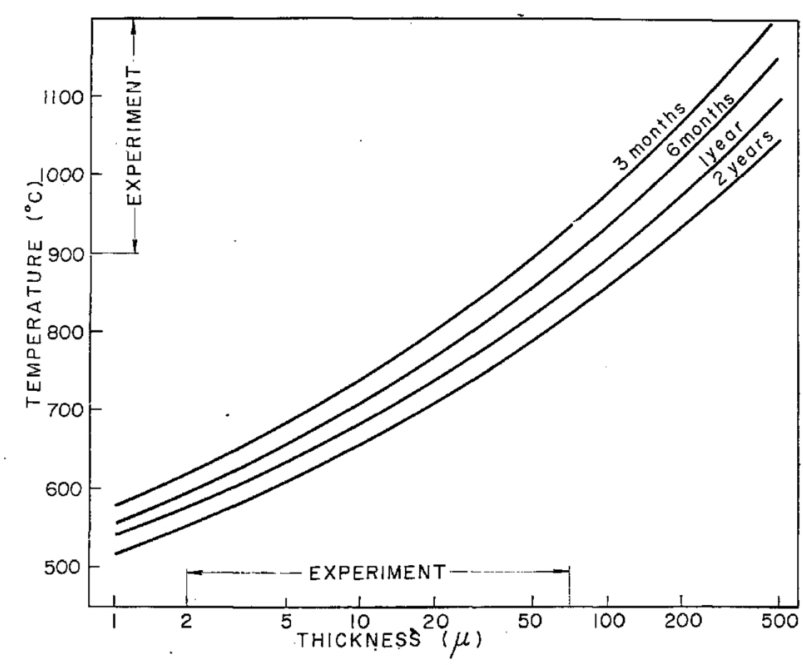

Fig. 4 Thickness of thorium metal for the carbide formation.

temperatures the reaction may proceed by different mechanisms. Also the reaction rate may be affected by neutron irradiation(15). However, the calculation was made to obtain a fundamental imformation.

Graphite matrix fuel reactors require a fairly high core temperature, but the temperature of the blanket is below the experimental range. Assuming that the same mechanism can be applied at temperatures lower than the experimental range, the rate constants at lower temperatures were obtained from the exprapolated line of $\mathrm{a}$ in Fig. 2. The relations between temperature and thickness of thorium which will reactto form carbide in $0.25,0.5,1$ and 2 years ${ }^{(16)}$ are shown in Fig. 3. The thickness of the carbide can be obtained by multiplying by $11.2 / 10.7$, the ratio of the Th and ThC, densities because the carbide film formed at those temperatures is thorium monocarbide only.

(15) G.J. Diens: Reactivity of Solids, (1961), 416. Elsvier Publishing Co.

(16) A.T. Gresky: Geneva Conf. Paper P/540 9 (1955), 505. 